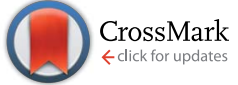

Cite this: J. Mater. Chem. A, 2016, 4, 6630

Received 23rd January 2016 Accepted 2nd April 2016

DOI: 10.1039/c6ta00648e

www.rsc.org/MaterialsA

\section{Ionic liquid-derived $\mathrm{Fe}-\mathrm{N} / \mathrm{C}$ catalysts for highly efficient oxygen reduction reaction without any supports, templates, or multi-step pyrolysis $\dagger$}

\author{
Fei He, ${ }^{a}$ Xinghua Chen, ${ }^{a}$ Yanfei Shen, ${ }^{b}$ Ying Li, ${ }^{a}$ Anran Liu, ${ }^{a}$ Songqin Liu, ${ }^{a}$ \\ Toshiyuki Moric and Yuanjian Zhang*a
}

\begin{abstract}
The development of efficient and low-cost non-precious-metal electrocatalysts such as $\mathrm{Fe}-\mathrm{N} / \mathrm{C}$ for the oxygen reduction reaction (ORR) is crucial for fuel cells and metal-air batteries. Here, we report a class of highly efficient $\mathrm{Fe}-\mathrm{N} / \mathrm{C}$ electrocatalysts derived from versatile imidazolium-based ionic liquids (ILs) with a halogen-coordinated iron anion. Without any supports, templates, or multi-step pyrolysis, the as-prepared $\mathrm{Fe}-\mathrm{N} / \mathrm{C}$ catalysts exhibited superior activity in the ORR to the state-of-the-art Pt/C in alkaline electrolytes by $44 \mathrm{mV}$ in half-wave potential. More interestingly, owing to the versatile configuration of the imidazolium-based IL precursors, a diverse range of catalyst structures was successfully modulated. Based on this, it was clearly revealed that the electrical conductivity, type/amount of $\mathrm{N}$ dopants, and "effective porosity" (not the conventional total surface area) jointly determined the electrocatalytic activity. A pivotal radar chart is further proposed to successfully predict activity in the ORR merely from the structures of Fe-N/C catalysts. The proposed ILs platform would provide a valuable toolbox for the molecular design of precursors to tune the structures of $\mathrm{Fe}-\mathrm{N} / \mathrm{C}$ electrocatalysts towards excellent activity in the ORR in a highly flexible manner, and facilitate the long-term challenging study of relationships between processing, structure and activity.
\end{abstract}

\section{Introduction}

The replacement of noble metals in key technologies such as proton exchange membrane fuel cells (PEMFCs) and metal-air batteries is of global importance for sustainable energy. ${ }^{1-5}$ An area of particular promise for non-precious-metal catalysts is doped carbon. ${ }^{6-8}$ Inspired by macrocyclic cobalt phthalocyanines, which have well-defined nitrogen-coordinated metal ion centers, ${ }^{9} \mathrm{M}-\mathrm{N} / \mathrm{C}$ catalysts (M represents, e.g., Fe, Co, and $\mathrm{Cu}$ ) have been commonly developed by the high-temperature pyrolysis of mixtures of transition metals and $\mathrm{C} / \mathrm{N}$-containing molecules. ${ }^{10-15}$ In general, the activities in the ORR of $\mathrm{M}-\mathrm{N} / \mathrm{C}$ catalysts obtained by conventional preparation strategies, including the physical mixture of individual $\mathrm{C} / \mathrm{N} / \mathrm{M}$-containing precursors, ${ }^{\mathbf{1 6}, 17}$ coordination of $\mathrm{N}$-containing polymers with metal ions ${ }^{\mathbf{1 8}}$ and wet impregnation, ${ }^{\mathbf{1 9}}$ are significantly

\footnotetext{
ajiangsu Province Hi-Tech Key Laboratory for Bio-Medical Research, Jiangsu Optoelectronic Functional Materials and Engineering Laboratory, School of Chemistry and Chemical Engineering, Southeast University, Nanjing 211189, China. E-mail: Yuanjian.Zhang@seu.edu.cn

${ }^{b}$ Medical School, Southeast University, Nanjing 210009, China

${ }^{c}$ Global Research Center for Environment and Energy Based on Nanomaterials Science (GREEN), National Institute for Materials Sciences (NIMS), 1-1 Namiki, Ibaraki, 3050044, Japan
}

$\uparrow$ Electronic supplementary information (ESI) available. See DOI: 10.1039/c6ta00648e influenced by several factors such as the molecular structure of precursors, ${ }^{\mathbf{2 0 , 2 1}}$ the extent of the dispersion/coordination of metal ions in precursors, ${ }^{22,23}$ and the diversity of interfaces among precursors, templates and supports. ${ }^{24,25}$ In this context, the validity of investigating the structure-function relationships of $\mathrm{M}-\mathrm{N} / \mathrm{C}$ catalysts is rendered questionable by the complexities of these factors. Therefore, it is highly desirable to minimize the number of variable conditions in a system in a relatively acceptable way. In this regard, ionic liquids (ILs), which have otherwise been recognized simply as green solvents, may have the potential to address this challenge via the free combination of task-specific anions and cations. ${ }^{26,27}$ Very recently, several pioneering works revealed that $\mathrm{M}-\mathrm{N} / \mathrm{C}$ catalysts derived from some ILs exhibit outstanding electrocatalytic activity in the ORR, but additional carbon supports, ${ }^{28,29}$ porous hard/soft templates $^{\mathbf{3 0 , 3 1}}$ or sophisticated multiple pyrolysis steps ${ }^{\mathbf{2 9}}$ were required, which still makes the research process complicated.

Here, we report that imidazolium-based ILs with a halogencoordinated iron anion can be developed as a class of single precursors for the one-step pyrolysis of $\mathrm{Fe}-\mathrm{N} / \mathrm{C}$ catalysts with excellent electrocatalytic activity in the ORR, which even surpassed that of commercially available $\mathrm{Pt} / \mathrm{C}$ in alkaline electrolytes. It was observed that with respect to previous precursors the imidazolium-based ILs were affected by fewer of the aforementioned influences in preparing $\mathrm{Fe}-\mathrm{N} / \mathrm{C}$ catalysts because of their uniform homogeneous distribution of Fe ions 
on the molecular level and no requirement for any supports, templates or multiple pyrolysis steps. Interestingly, the versatile configurations of the imidazolium-based IL precursors could modulate a diverse range of features of catalysts such as porosity, surface area, graphitization, electrical conductivity, and doping by $\mathrm{N}$ atoms in the as-prepared $\mathrm{Fe}-\mathrm{N} / \mathrm{C}$ catalysts. As was successfully demonstrated, this in turn largely facilitated the discovery of structure-activity relationships and made the prediction of the activity in the ORR of Fe-N/C catalysts merely from their structural features possible. The proposed ILs platform would provide the scope to modulate the molecular design of precursors for synthesizing a range of $\mathrm{M}-\mathrm{N} / \mathrm{C}$ catalysts with different structures towards excellent activity in the ORR in a highly flexible manner and facilitate the long-term challenging study of relationships between processing, structure and activity.

\section{Experimental section}

\section{Chemicals}

All chemicals and solvents were of analytical grade and were purchased from Aladdin Chemistry Co., Ltd. or Sinopharm Chemical Reagent Co., Ltd. and used without further purification. Ultrapure water $(18.2 \mathrm{M} \Omega \mathrm{cm})$ was obtained from a Thermal Smart2 water purification system (USA).

\section{Preparation of ionic liquid precursors}

Detailed synthetic procedures of MIm + Fe and each IL (IL-1, IL2, IL-3, IL-3' , and IL-4) are listed as follows. The general approach used for the preparation of ionic liquid precursors is shown in Scheme 1.

\section{Synthesis of MIm + Fe}

$N$-Methylimidazole $(8.21 \mathrm{~g}, 100 \mathrm{mmol})$, anhydrous $\mathrm{FeCl}_{3}(16.2 \mathrm{~g}$, $100 \mathrm{mmol})$ and dry EtOH $(100 \mathrm{~mL})$ were mixed in a roundbottom flask and stirred at RT under a $\mathrm{N}_{2}$ atmosphere for $8 \mathrm{~h}$. After that, EtOH was removed via rotary evaporation. The product was dried for $10 \mathrm{~h}$ at $80{ }^{\circ} \mathrm{C}$ under vacuum to yield MIm + Fe.

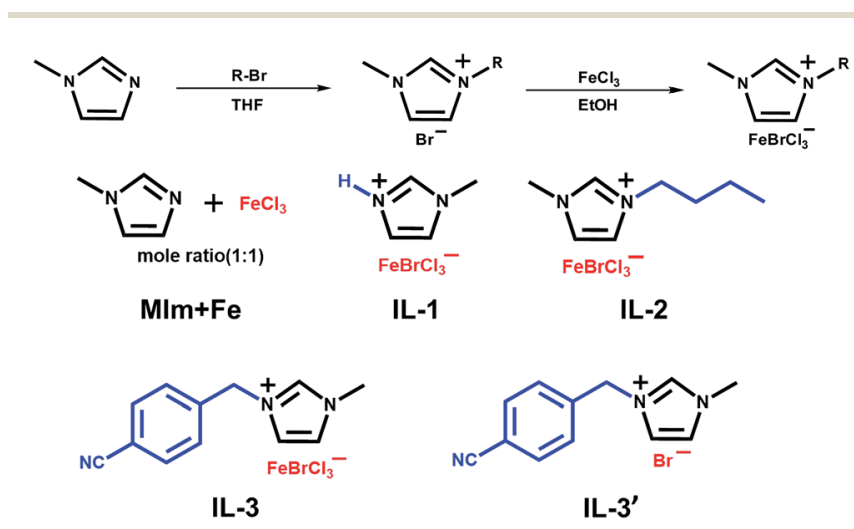

Scheme 1 General synthetic steps and chemical structures of imidazolium-based ionic liquid precursors (IL-1, IL-2, IL-3 and IL-3') and a physical mixture of $\mathrm{N}$-methylimidazole and ferric chloride $(\mathrm{MIm}+\mathrm{Fe})$.

\section{Synthesis of IL-1}

$\mathrm{N}$-Methylimidazole hydrobromide was prepared by an acidbase neutralization reaction. $N$-Methylimidazole $(8.21 \mathrm{~g}$, $100 \mathrm{mmol})$ and dry THF $(50 \mathrm{~mL})$ were mixed in a round-bottom flask with magnetic stirring. After cooling to $0{ }^{\circ} \mathrm{C}$ in an ice-water bath, an excess of hydrogen bromide, which was prepared from phosphorus tribromide and water, was added to the reaction mixture for $2 \mathrm{~h}$. Then, THF was removed via rotary evaporation. The crude product was rinsed with cold diethyl ether. The top layer was decanted off and this procedure was repeated three times. The collected oil was dried for $6 \mathrm{~h}$ at $80{ }^{\circ} \mathrm{C}$ under vacuum to yield $N$-methylimidazole hydrobromide (15.8 g, yield: $97 \%)$. ${ }^{1} \mathrm{H}$ NMR (DMSO-d 6 , $\delta$, ppm, TMS): $3.88\left(3 \mathrm{H}, \mathrm{CH}_{3} \mathrm{~N}-\right), 7.69,7.74$ and $9.18(3 \mathrm{H}$, imidazole protons $), 14.21\left(1 \mathrm{H},-\mathrm{N}^{+} H-\right)$. Then, $N$-methylimidazole hydrobromide $(15.8 \mathrm{~g}, 97 \mathrm{mmol})$, anhydrous $\mathrm{FeCl}_{3}(15.7 \mathrm{~g}, 97 \mathrm{mmol})$ and dry EtOH $(100 \mathrm{~mL})$ were mixed in a round-bottom flask and stirred at RT under a $\mathrm{N}_{2}$ atmosphere for $8 \mathrm{~h}$. After that, EtOH was removed via rotary evaporation. The crude product was rinsed with cold diethyl ether three times. The collected dark brown oil was dried for $10 \mathrm{~h}$ at $80{ }^{\circ} \mathrm{C}$ under vacuum to yield IL-1 (29.9 g, yield: 95\%). Raman $\left(\mathrm{cm}^{-1}\right)$ : 221, 242 and 266 (Fe-Br), 328 (Fe-Cl).

\section{Synthesis of IL-2}

1-Butyl-3-methylimidazolium bromide was prepared by a quaternization reaction. ${ }^{32,33} \mathrm{~N}$-Methylimidazole $(8.21 \mathrm{~g}, 100$ mmol), 1-bromobutane $(13.7 \mathrm{~g}, 100 \mathrm{mmol})$, and dry THF $(50 \mathrm{~mL})$ were mixed in a round-bottom flask and stirred with refluxing at $80{ }^{\circ} \mathrm{C}$ under a $\mathrm{N}_{2}$ atmosphere for $24 \mathrm{~h}$. After cooling to RT, THF was removed via rotary evaporation. The crude product was rinsed with cold diethyl ether. The top layer was decanted off and this procedure was repeated three times. The collected oil was dried for $6 \mathrm{~h}$ at $80{ }^{\circ} \mathrm{C}$ under vacuum to yield 1butyl-3-methylimidazolium bromide (20.8 g, yield: $95 \%) .{ }^{1} \mathrm{H}$ NMR (DMSO-d ${ }_{6}, \delta$, ppm, TMS): $0.89\left(3 \mathrm{H}, \mathrm{CH}_{3} \mathrm{CH}_{2} \mathrm{CH}_{2}-\right), 1.25$ $\left(2 \mathrm{H}, \mathrm{CH}_{3} \mathrm{CH}_{2} \mathrm{CH}_{2}-\right), 1.76\left(2 \mathrm{H}, \mathrm{CH}_{3} \mathrm{CH}_{2} \mathrm{CH}_{2}-\right), 3.87\left(3 \mathrm{H}, \mathrm{CH}_{3} \mathrm{~N}-\right)$, $4.19\left(2 \mathrm{H},-\mathrm{CH}_{2} \mathrm{CH}_{2} \mathrm{~N}-\right), 7.76,7.83$ and 9.29 (3H, imidazole protons). Then, 1-butyl-3-methylimidazolium bromide (20.8 g, $95 \mathrm{mmol})$, anhydrous $\mathrm{FeCl}_{3}(15.4 \mathrm{~g}, 95 \mathrm{mmol})$ and dry $\mathrm{EtOH}$ $(100 \mathrm{~mL})$ were mixed in a round-bottom flask and stirred at RT under a $\mathrm{N}_{2}$ atmosphere for $8 \mathrm{~h}$. After that, $\mathrm{EtOH}$ was removed via rotary evaporation. The crude product was rinsed with cold diethyl ether. The collected dark brown oil was dried for $10 \mathrm{~h}$ at $80{ }^{\circ} \mathrm{C}$ under vacuum to yield IL-2 (34.4 g, yield: 95\%). Raman $\left(\mathrm{cm}^{-1}\right): 221,242$ and 266 (Fe-Br), 328 (Fe-Cl).

\section{Synthesis of IL-3}

1-(4-Cyanobenzyl)-3-methylimidazolium bromide (IL-3') was prepared by a quaternization reaction. ${ }^{32,33} \mathrm{~N}$-Methylimidazole (8.21 g, $100 \mathrm{mmol}$ ), 4-cyanobenzyl bromide (19.6 g, $100 \mathrm{mmol}$ ), and dry THF $(50 \mathrm{~mL})$ were mixed in a round-bottom flask and stirred with refluxing at $80{ }^{\circ} \mathrm{C}$ under a $\mathrm{N}_{2}$ atmosphere for $24 \mathrm{~h}$. After cooling to RT, THF was removed via rotary evaporation. The crude product was rinsed with cold diethyl ether. The top layer was decanted off and this procedure was repeated three 
times. The collected solid was dried for $6 \mathrm{~h}$ at $80{ }^{\circ} \mathrm{C}$ under vacuum to yield 1-(4-cyanobenzyl)-3-methylimidazolium bromide (26.4 g, yield: $95 \%) .{ }^{1} \mathrm{H}$ NMR (DMSO- $\left.\mathrm{d}_{6}, \delta, \mathrm{ppm}, \mathrm{TMS}\right)$ : $3.87\left(3 \mathrm{H}, \mathrm{CH}_{3} \mathrm{~N}-\right), 5.58\left(2 \mathrm{H}, \mathrm{CNC}_{6} \mathrm{H}_{4} \mathrm{CH}_{2} \mathrm{~N}-\right), 7.60,7.62,7.92$ and $7.94(4 \mathrm{H}$, benzene ring protons), 7.77, 7.84 and 9.32 (3H, imidazole protons). Then, 1-(4-cyanobenzyl)-3-methylimidazolium bromide (26.4 g, $95 \mathrm{mmol}$ ), anhydrous $\mathrm{FeCl}_{3}$ $(15.4 \mathrm{~g}, 95 \mathrm{mmol})$ and dry EtOH $(100 \mathrm{~mL})$ were mixed in a round-bottom flask and stirred at RT under a $\mathrm{N}_{2}$ atmosphere for $8 \mathrm{~h}$. After that, EtOH was removed via rotary evaporation. The crude product was rinsed with cold diethyl ether. The collected solid was dried for $10 \mathrm{~h}$ at $80{ }^{\circ} \mathrm{C}$ under vacuum to yield IL-3 (39.7 g, yield: 95\%). Raman $\left(\mathrm{cm}^{-1}\right)$ : 221, 242 and 266 (Fe-Br), 328 (Fe-Cl).

\section{Synthesis of IL-4}

1-Benzyl-3-methylimidazolium bromide was prepared by a quaternization reaction. ${ }^{32,33} \mathrm{~N}$-Methylimidazole $(8.21 \mathrm{~g}, 100 \mathrm{mmol})$, benzyl bromide $(17.1 \mathrm{~g}, 100 \mathrm{mmol})$, and dry THF $(50 \mathrm{~mL})$ were mixed in a round-bottom flask and stirred with refluxing at $80^{\circ} \mathrm{C}$ under a $\mathrm{N}_{2}$ atmosphere for $24 \mathrm{~h}$. After cooling to RT, THF was removed via rotary evaporation. The crude product was rinsed with cold diethyl ether. The top layer was decanted off and this procedure was repeated three times. The collected oil was dried for $6 \mathrm{~h}$ at $80{ }^{\circ} \mathrm{C}$ under vacuum to yield 1-benzyl-3-methylimidazolium bromide (24.0 g, yield: $95 \%) .{ }^{1} \mathrm{H}$ NMR $\left(\mathrm{DMSO}_{6}, \delta\right.$, ppm, TMS): $3.86\left(3 \mathrm{H}, \mathrm{CH}_{3} \mathrm{~N}-\right)$, $5.44\left(2 \mathrm{H}, \mathrm{C}_{6} \mathrm{H}_{5} \mathrm{CH}_{2} \mathrm{~N}-\right)$, 7.35-7.45 $(5 \mathrm{H}$, benzene ring protons), 7.72, 7.81 and $9.31(3 \mathrm{H}$, imidazole protons). Then, 1-benzyl-3-methylimidazolium bromide (24.0 g, $95 \mathrm{mmol})$, anhydrous $\mathrm{FeCl}_{3}(15.4 \mathrm{~g}, 95 \mathrm{mmol})$ and dry EtOH $(100 \mathrm{~mL})$ were mixed in a round-bottom flask and stirred at RT under a $\mathrm{N}_{2}$ atmosphere for $8 \mathrm{~h}$. After that, EtOH was removed via rotary evaporation. The crude product was rinsed with cold diethyl ether. The collected dark brown oil was dried for $10 \mathrm{~h}$ at $80{ }^{\circ} \mathrm{C}$ under vacuum to yield IL-4 (36.6 g, yield: 93\%). Raman $\left(\mathrm{cm}^{-1}\right): 221,242$ and $266(\mathrm{Fe}-\mathrm{Br}), 328(\mathrm{Fe}-\mathrm{Cl})$.

\section{Preparation of catalysts}

Doped carbon catalysts were prepared by heating the respective precursors in a furnace at $600^{\circ} \mathrm{C}, 700{ }^{\circ} \mathrm{C}, 750^{\circ} \mathrm{C}$ and $800{ }^{\circ} \mathrm{C}$ for $1 \mathrm{~h}$ in a nitrogen atmosphere at a ramp rate of $10{ }^{\circ} \mathrm{C} \mathrm{min}^{-1}$. Thereafter, the obtained samples were ground to a powder, transferred to a round-bottom flask, ultrasonically dispersed in $25 \mathrm{~mL}$ of $37 \mathrm{wt} \% \mathrm{HCl}$, and stirred at RT overnight to remove excess iron species. Then, the doped carbonaceous part was isolated by centrifugation, washed with water and dried in vacuum at $80{ }^{\circ} \mathrm{C}$ overnight. The respective linear sweep voltammetry (LSV) curves showed that the catalyst calcined at $750{ }^{\circ} \mathrm{C}$ exhibited the best activity in the ORR (Fig. S9, see ESI $\dagger$ ). Acid treatment resulted in an increase in activity in the ORR accompanied by a decrease in $\mathrm{Fe}$ content such as in IL-3-C (Fig. S11 and Table S1, see ESI $\dagger$ ). After acid treatment, the total Fe content in all catalysts was estimated to range from $0.23 \mathrm{wt} \%$ to $0.68 \mathrm{wt} \%$ by XPS (Table S1, see ESI $\dagger$ ), which was sufficient for an effective catalytic ORR. ${ }^{25}$ Therefore, the influence of the concentration of Fe species on the ORR was not comprehensively studied in this work.

\section{Electrochemical measurements}

The evaluation of the activity in the ORR of various electro-

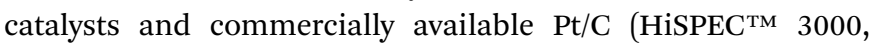
$20 \mathrm{wt} \%$ Pt on carbon black, Johnson Matthey) was performed in a standard three-electrode glass cell on a CHI700E workstation (CH Instruments, USA). A rotating disk glassy carbon electrode modified by an electrocatalyst was used as the working electrode. Pt wire and $\mathrm{Ag} / \mathrm{AgCl}$ (saturated $\mathrm{KCl}$ ) were used as the counter and reference electrodes, respectively. The procedure of modification of the working electrode was as follows: $10 \mu \mathrm{L}$ of a suspension of an electrocatalyst in ethanol $\left(2 \mathrm{mg} \mathrm{mL}^{-1}\right)$ was cast on the pre-polished surface of a rotating glassy carbon electrode (3 $\mathrm{mm}$ diameter) or a rotating ring-disk electrode ( $4 \mathrm{~mm}$ diameter), resulting in a catalyst loading of $283 \mu \mathrm{g} \mathrm{cm}{ }^{-2}$. The electrode was allowed to dry at RT and heated in air at $60{ }^{\circ} \mathrm{C}$ for $15 \mathrm{~min}$. After that, $5 \mu \mathrm{L}$ Nafion ( $0.05 \mathrm{wt} \%)$ was further cast on the surface of the electrode. Then, the electrode was again dried at RT and heated in air at $60{ }^{\circ} \mathrm{C}$ for $15 \mathrm{~min}$.

For the ORR test, $0.1 \mathrm{M} \mathrm{KOH}(\mathrm{pH}=13), 0.1 \mathrm{M} \mathrm{Na}_{2} \mathrm{HPO}_{4} /$ $\mathrm{NaH}_{2} \mathrm{PO}_{4}$ solution (PBS, $\mathrm{pH}=7.4$ ), and $0.5 \mathrm{M} \mathrm{H}_{2} \mathrm{SO}_{4}$ for alkaline, neutral and acidic conditions, respectively, were purged with high-purity $\mathrm{O}_{2}$ gas for 30 minutes and thereafter the electrolyte was protected by a flow of $\mathrm{O}_{2}$. Activity in the ORR was measured using linear sweep voltammetry (LSV) at the rotating electrode (RRDE-3A, BAS, Japan). LSV was performed at a scan rate of $10 \mathrm{mV} \mathrm{s}^{-1}$. The onset potential $\left(E_{\text {onset }}\right)$ was defined as the potential at which the current density reached $5 \%$ of the diffusion-limiting current density in the cathodic scan. The half-wave potential $\left(E_{1 / 2}\right)$ was defined as the potential at which the current density reached $50 \%$ of the diffusion-limiting current density in the cathodic scan. ${ }^{5}$

The kinetic limiting current density $\left(J_{\mathrm{K}}\right)$ for the ORR can be derived from the experimental data using the Koutecky-Levich equation for rotating disk electrodes: ${ }^{34}$

$$
\begin{gathered}
\frac{1}{J}=\frac{1}{J_{\mathrm{K}}}+\frac{1}{J_{\mathrm{L}}}=\frac{1}{J_{\mathrm{K}}}+\frac{1}{B \omega^{1 / 2}} \\
B=0.62 n F C_{0}\left(D_{0}\right)^{\frac{2}{3}} \nu^{-\frac{1}{6}} \\
J_{\mathrm{K}}=n F k C_{0}
\end{gathered}
$$

in which $J$ is the measured current density, $J_{\mathrm{K}}$ and $J_{\mathrm{L}}$ are the kinetic and diffusion-limiting current densities, $\omega$ is the angular velocity of the rotating electrode $(\omega=2 \pi N$, where $N$ is the linear speed of rotation), $n$ is the electron transfer number in the ORR, $F$ is the Faraday constant (96485 $\mathrm{C} \mathrm{mol}^{-1}$ ), $C_{0}$ is the concentration of $\mathrm{O}_{2}, D_{0}$ is the diffusion coefficient of $\mathrm{O}_{2}, \nu$ is the kinematic viscosity of the electrolyte, and $k$ is the rate constant for electron transfer. Because the electrolyte was $\mathrm{O}_{2}$-saturated $0.1 \mathrm{M} \mathrm{KOH}$ in this report, the values of $C_{0}, D_{0}$ and $\nu$ were $1.2 \times$ $10^{-3} \mathrm{M}, 1.9 \times 10^{-5} \mathrm{~cm}^{2} \mathrm{~s}^{-1}$, and $0.01 \mathrm{~cm}^{2} \mathrm{~s}^{-1}$, respectively.

To determine the yield of $\mathrm{H}_{2} \mathrm{O}_{2}$, the ring potential was set to $0.5 \mathrm{~V}(\mathrm{Ag} / \mathrm{AgCl})$ to oxidize the $\mathrm{H}_{2} \mathrm{O}_{2}$ transferred from the $\mathrm{GC}$ disk electrode. The yield of $\mathrm{H}_{2} \mathrm{O}_{2}$ and the electron transfer number $(n)$ were calculated by the following equations: ${ }^{35}$ 


$$
\begin{gathered}
\mathrm{H}_{2} \mathrm{O}_{2}(\%)=200 \times \frac{I_{\mathrm{R}} / N_{0}}{\left(I_{\mathrm{R}} / N_{0}\right)+I_{\mathrm{D}}} \\
n=4 \times \frac{I_{\mathrm{D}}}{\left(I_{\mathrm{R}} / N_{0}\right)+I_{\mathrm{D}}}
\end{gathered}
$$

where $I_{\mathrm{D}}$ and $I_{\mathrm{R}}$ are the disk and ring currents, respectively, and $N_{0}$ is the ring collection efficiency. The value of $N_{0}$ was determined to be 0.42 in a solution of $5 \mathrm{mM} \mathrm{K}_{4} \mathrm{Fe}(\mathrm{CN})_{6}+5 \mathrm{mM}$ $\mathrm{K}_{3} \mathrm{Fe}(\mathrm{CN})_{6}$.

\section{Characterization}

NMR spectra were recorded on a Bruker Avance III $400 \mathrm{MHz}$ NMR spectrometer (Germany). Thermogravimetric analysis (TGA) was conducted on a PerkinElmer Pyris 1 analyzer. Scanning electron microscopy (SEM) images were recorded on a Hitachi S-4800 electron microscope (Japan). Transmission electron microscopy (TEM) was carried out on a FEI Tecnai G2 microscope (USA) at an accelerating voltage of $200 \mathrm{kV}$. Nitrogen adsorption-desorption isotherms were measured at $77 \mathrm{~K}$ with a Quantachrome Autosorb iQ one-station adsorption instrument (USA). Samples were degassed at $300{ }^{\circ} \mathrm{C}$ for $8 \mathrm{~h}$ at reduced pressure before measurement. The surface area was calculated by the Brunauer-Emmett-Teller (BET) method. The surface area of micropores and mesopores was calculated by the $V-t$ method. The pore size distributions (PSD) were calculated based on the model of slit/cylindrical pores on carbon using the adsorption branch of the isotherms by the QSDFT method. Raman spectra were recorded on a Thermo DXR 532 Raman spectrometer (USA) with a laser excitation wavelength of $532 \mathrm{~nm}$. X-ray diffraction (XRD) was carried out on a Rigaku SmartLab 3 (Japan) X-ray diffractometer equipped with graphite-monochromated $\mathrm{Cu} \mathrm{K} \alpha$ radiation $(\lambda=1.54056 \AA)$. X-ray photoelectron spectroscopy (XPS) experiments were performed with a Thermo Theta Probe (USA) spectrometer using monochromated $\mathrm{Al} \mathrm{K} \alpha$ X-rays at $h \nu=1486.6 \mathrm{eV}$. Peak positions were internally referenced to the $\mathrm{C} 1 \mathrm{~s}$ peak at $284.6 \mathrm{eV}$. Conductivity measurements were performed by confining a sample between two iron discs and measuring the electrical resistance of the sample by chronocoulometry on a Gamry Reference 600 potentiostat (USA).

\section{Results and discussion}

In the first set of experiments, the H-substituted imidazoliumbased IL bearing a halogen-coordinated iron anion (IL-1, Scheme 1) was directly pyrolyzed at $750{ }^{\circ} \mathrm{C}$ under a $\mathrm{N}_{2}$ atmosphere without any supports, templates or multiple pyrolysis steps (see details in the Experimental section), and the as-obtained product was denoted as IL-1-C. The cyclic voltammetry (CV) curve of IL-1-C showed a well-defined cathodic peak in $\mathrm{O}_{2}$-saturated $0.1 \mathrm{M} \mathrm{KOH}$ with a peak potential that was $49 \mathrm{mV}$ higher than that of commercially available $\mathrm{Pt} / \mathrm{C}$ (20 wt\%), which suggests that IL-1-C has excellent electrocatalytic activity in the ORR (Fig. S1, see ESI $\dagger$ ). To exclude diffusion-controlled current, hydrodynamic linear sweep voltammetry (LSV) using a rotating disk electrode (RDE) was further performed. It was observed that the onset potential $\left(E_{\text {onset }}=-11 \mathrm{mV}\right)$ and half-wave potential $\left(E_{1 / 2}=-99 \mathrm{mV}\right)$ of IL-1-C were $56 \mathrm{mV}$ and $44 \mathrm{mV}$ higher, respectively, than those of Pt/C (Fig. 1a), which was in agreement with the Tafel plots in the low overpotential region (Fig. 1b). By varying the speed of rotation (Fig. S2, see ESI $\dagger$ ) and using the Koutecky-Levich (K-L) equation, the kinetic limiting current density $\left(J_{\mathrm{K}}\right)$ was calculated and found to be comparable to that of Pt/C (Fig. S3, see ESI $\dagger$ ). Rotating ring-disk electrode (RRDE) measurements showed that the yields of $\mathrm{H}_{2} \mathrm{O}_{2}$ during the ORR in the kinetic limiting region for IL-1-C were below 5.5\%. Based on the results of the RRDE measurements and eqn (5) (see details in the Experimental section), the calculated electron transfer number $(n)$ for the ORR was 3.89-4.00, which was similar to that of Pt/C (Fig. 1c). Moreover, as indicated by the fact that the Tafel slope was almost the same $\left(\sim 60 \mathrm{mV} \mathrm{dec}^{-1}\right)$, the transfer of the first electron in the ORR catalyzed by IL-1-C was probably the ratedetermining step, as with Pt/C. ${ }^{36}$ The as-prepared IL-1-C also exhibited significant catalytic activity in the ORR in neutral and acidic solutions, but this was poorer in comparison with the activity in alkaline solution, which was presumably because of the different surface charge state of $\mathrm{N}$-doped carbon at different pH values ${ }^{12,13}$ (Fig. S4, see ESI $\dagger$ ). To discover the crucial role of well-distributed iron on the molecular level in defining the structures of the catalysts, a physical mixture of $\mathrm{N}$-methylimidazole and an iron salt in a molar ratio of $1: 1(\mathbf{M I m}+\mathbf{F e}$, Scheme 1) was also prepared as a control. In sharp contrast, the values of $E_{\text {onset }}, E_{1 / 2}, J_{\mathrm{K}}$ and the electron transfer number of MIm + Fe-C (obtained by carbonization of $\mathbf{M I m}+\mathbf{F e}$ ) were inferior to those of IL-1-C (Fig. 1a), which evidently revealed the importance of a homogeneous distribution of iron ions in the
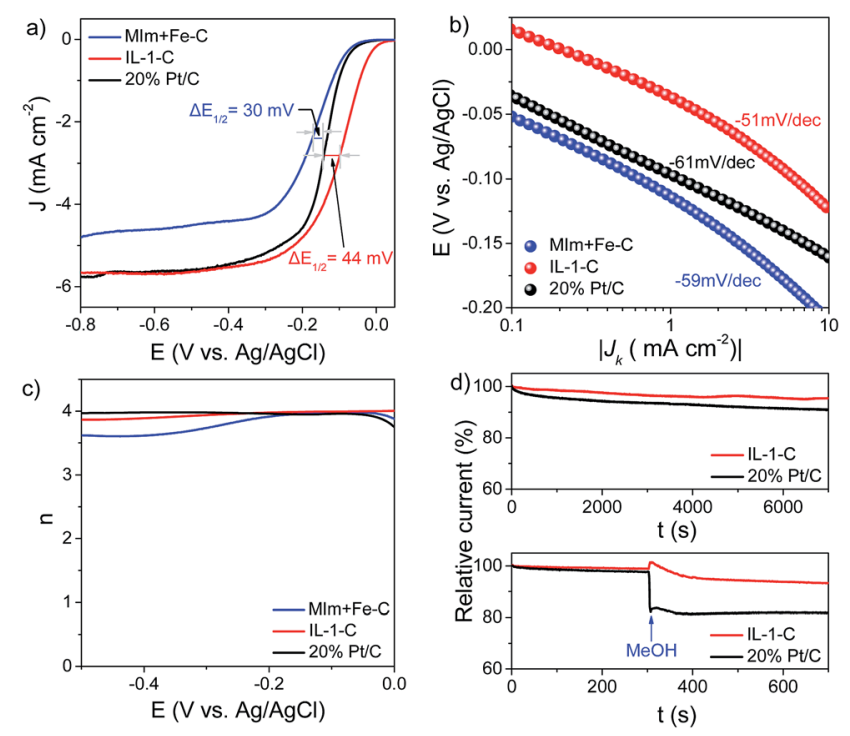

Fig. 1 Performance in the ORR of catalysts. (a) LSV curves of MIm + $\mathrm{Fe}-\mathrm{C}$, IL-1-C and 20\% Pt/C at $1600 \mathrm{rpm}$. (b) Tafel plots of Mlm + Fe-C, IL-1-C and 20\% Pt/C. (c) Electron transfer number of MIm + Fe-C, IL1-C and $20 \% \mathrm{Pt} / \mathrm{C}$ based on RRDE data. (d) Current-time $(I-t)$ response and evaluation of the crossover effect from methanol oxidation of IL-1-C and 20\% Pt/C. RDE and RRDE data were recorded in $\mathrm{O}_{2}$-saturated $0.1 \mathrm{M} \mathrm{KOH}$. Sweep rate: $10 \mathrm{mV} \mathrm{s}^{-1}$. 
precursors on the molecular level for the enhancement of the electrocatalytic activities of the resulting catalysts. In addition, IL-1-C exhibited high stability and little crossover effect from methanol oxidation compared with Pt/C (Fig. 1d). In this regard, one-step pyrolysis of imidazolium-based ILs bearing a halogencoordinated iron anion without any supports or templates could be developed as a highly efficient way for preparing $\mathrm{Fe}-\mathrm{N} / \mathrm{C}$ catalysts for the ORR that even surpass commercially available $\mathrm{Pt} / \mathrm{C}$ in alkaline electrolytes, thus providing a substantial platform with minimal influencing factors for studying the structure-activity relationships of $\mathrm{Fe}-\mathrm{N} / \mathrm{C}$ catalysts.

The most attractive characteristic of ILs is that their properties can be easily manipulated by the free combination of numerous cations and anions. This feature allowed us to further investigate the general relationship between the molecular structures of IL-based precursors, the structures of catalysts, and the activities of catalysts, thus helping us to not only prepare more efficient $\mathrm{Fe}-\mathrm{N} / \mathrm{C}$ catalysts for the ORR but also to deepen our understanding of the fundamental mechanism. For this, IL precursors bearing a longer flexible alkyl chain substituent (IL-2), a more rigid cyanobenzyl substituent (IL-3), or a counter anion without any iron content (IL-3') were synthesized and carbonized to give the final catalysts. (The rigidity and flexibility are from the point of view of organic chemistry. For instance, a benzene ring is more rigid than an alkane.) The hydrodynamic LSV curves in Fig. 2a show that their catalytic activity in the ORR evidently varied. Detailed values of $E_{\text {onset }}, E_{1 / 2}, J_{\mathrm{K}}$, and the electron transfer number of the as-obtained catalysts for the ORR, together with typical textural information, are summarized in Table 1.

At first glance, IL-3'-C exhibited much lower activity in the ORR than all its counterparts, which suggests that an even distribution of iron ions in precursors is rather helpful for improving activity in the ORR. To obtain more insight into the differences in catalytic activity in the ORR, the crystalline graphitic structures of the as-prepared $\mathrm{Fe}-\mathrm{N} / \mathrm{C}$ catalysts were first determined by X-ray diffraction (XRD). Fig. 2b shows that all catalysts contained graphitic carbon, as confirmed by the characteristic XRD peaks at $\sim 26.2^{\circ}, 42.6^{\circ}$, and $44.4^{\circ}$, corresponding to the (002), (100) and (101) diffractions, ${ }^{37}$ respectively. Interestingly, the extent of graphitization decreased (IL-1-C > IL-2-C > IL-3-C) as the rigidity of the substituent on the imidazolium cation increased. For example, for IL-1, which only contained a $\mathrm{H}$ substituent, two additional (004) and (110) reflections, which indicated an even higher extent of graphitization, were observed after pyrolysis and were presumably due to a strong tendency towards graphitization for flexible substituents (TGA curves are in Fig. S5, see ESI $†$ ). Moreover, for MIm + Fe and IL-1, it was observed that the extent of graphitization of the latter was higher after pyrolysis, which implies that well-distributed iron on the molecular level also favoured graphitization. Accordingly, the TEM/SEM images in Fig. 3 show that IL-1-C was more characterized by a sheet-like texture in comparison with the other $\mathrm{Fe}-\mathrm{N} / \mathrm{C}$ catalysts. The Raman spectra also confirmed the different extent of graphitization and were highly consistent with the XRD results (Fig. S6, see ESI $\dagger$ ). Hence, both the flexibility of the substituent in the
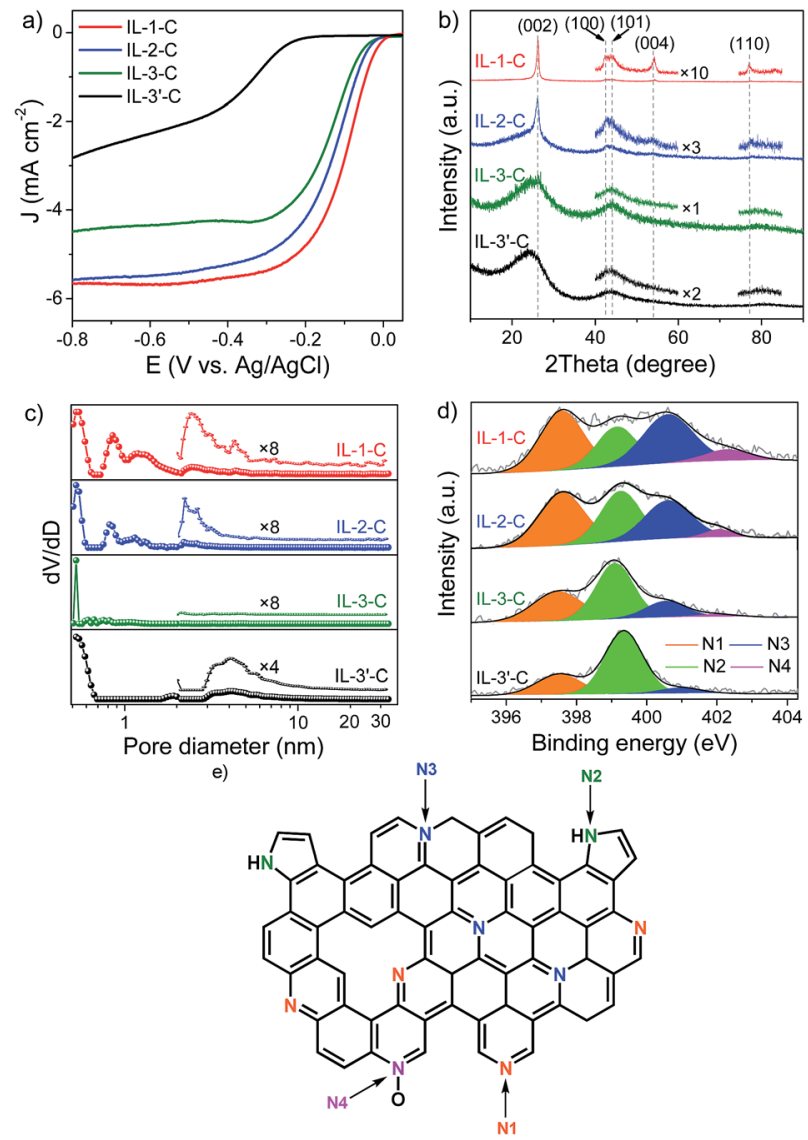

Fig. 2 ORR activity in the ORR and structural information of catalysts. LSV curves (a), XRD patterns (b), pore size distribution curves (c) and high-resolution N 1s XPS spectra (d) of IL-1-C, IL-2-C, IL-3-C and IL$3^{\prime}-\mathrm{C}$. N heterocyclic structures in catalysts (e). LSV was performed at $1600 \mathrm{rpm}$ at a sweep rate of $10 \mathrm{mV} \mathrm{s}^{-1}$ in $\mathrm{O}_{2}$-saturated $0.1 \mathrm{M} \mathrm{KOH} . \mathrm{N} 1$, N2, N3 and N4 represent pyridinic, pyrrolic, graphitic, and oxidized $\mathrm{N}^{+}-\mathrm{O}^{-}$nitrogen species, respectively.

cation and the even molecular distribution of iron in the anion of the IL precursors played an important role in increasing the extent of graphitization of the final $\mathrm{Fe}-\mathrm{N} / \mathrm{C}$ catalysts, which will be discussed below in turn regarding the facilitation of electron transfer in the ORR.

Because the surface area of catalysts largely determines the number of exposed active sites, ${ }^{24}$ the $\mathrm{N}_{2}$ adsorption-desorption isotherms of IL-1-C, IL-2-C, IL-3-C and IL-3'-C were investigated. Fig. S7 (see ESI $\dagger$ ) shows a large uptake of $\mathrm{N}_{2}$ and a hysteresis loop for all samples at a relative pressure $\left(p / p_{0}\right)$ of $c a .0 .001$ and $0.48-1.0$, respectively, which reveals the presence of both micro- and mesoporosity. Their BET surface areas were as high as 253 to $1242 \mathrm{~m}^{2} \mathrm{~g}^{-1}$. Pore size distributions were further analyzed by the density functional theory (DFT) method using the adsorption branch of the isotherm (Fig. 2c). For IL-1-C, IL-2-C and IL-3-C, it was observed that both micropores and mesopores exhibited a slight shift toward smaller sizes and the relative content of mesopores decreased gradually when the rigidity of the substituent on the imidazolium cation increased. Thus, without any templates, supports or multiple pyrolysis steps, we could regulate the porosity and surface area of $\mathrm{Fe}-\mathrm{N} / \mathrm{C}$ 
Table 1 Summary of activity in the ORR and typical textural information for MIm + Fe-C, IL-1-C, IL-2-C, IL-3-C, and IL-3'-C

\begin{tabular}{|c|c|c|c|c|c|c|c|c|c|}
\hline Catalyst & $E_{\text {onset }}^{a} \mathrm{mV}$ & $E_{1 / 2}^{b} \mathrm{mV}$ & $J_{\mathrm{K}}{ }^{c} \mathrm{~mA} \mathrm{~cm}^{-2}$ & $n^{d}$ & $\begin{array}{l}(\mathrm{N} 1+\mathrm{N} 3) / \\
\mathrm{N}_{\text {total }} e(\text { at } \%)\end{array}$ & $\begin{array}{l}\text { Relative specific } \\
\text { resistance }^{f}\end{array}$ & $\mathrm{SA}^{g} \mathrm{~m}^{2} \mathrm{~g}^{-1}$ & $\mathrm{MSA}^{h} \mathrm{~m}^{2} \mathrm{~g}^{-1}$ & $\mathrm{MC}^{i} \mathrm{~cm}^{3} \mathrm{~g}^{-1}$ \\
\hline $\mathrm{MIm}+\mathrm{Fe}-\mathrm{C}$ & -72 & -173 & 27.4 & 3.74 & 59.0 & 1.10 & 276 & 207 & 0.65 \\
\hline IL-2-C & -31 & -131 & 32.8 & 3.94 & 65.6 & 1.04 & 1010 & 91 & 0.16 \\
\hline IL-3-C & -34 & -137 & 20.4 & 3.90 & 49.2 & 1.4 & 1242 & 98 & 0.09 \\
\hline $\mathrm{IL}^{\prime} \mathbf{3}^{\prime}-\mathrm{C}$ & -212 & -379 & 0.9 & - & 33.6 & 1.12 & 253 & 148 & 0.11 \\
\hline
\end{tabular}

${ }^{a} E_{\text {onset }}$ was defined as the potential at which the current density reached $5 \%$ of the diffusion-limiting current density. ${ }^{b} E_{1 / 2}$ was defined as the potential at which the current density reached $50 \%$ of the diffusion-limiting current density. ${ }^{c} J_{\mathrm{K}}$ was calculated at $-0.3 \mathrm{~V}$ by the KouteckyLevich (K-L) equation. ${ }^{d}$ The electron transfer number $(n)$ was calculated at $-0.3 \mathrm{~V}$ by RRDE measurements. ${ }^{e} \mathrm{~N} 1$, N3 and $\mathrm{N}_{\text {total }}$ represent pyridinic $\mathrm{N}$, graphitic $\mathrm{N}$, and total $\mathrm{N}$, respectively. The total $\mathrm{N}$ content of all catalysts was estimated to the range from $2.22 \%$ to $5.01 \%$ by XPS. $f$ The relative specific resistance of catalysts was calculated by normalizing the measured specific resistance with that of a graphite reference. ${ }^{g}$ SA: surface area. ${ }^{h}$ MSA: mesopore surface area. ${ }^{i}$ MC: mesopore capacity.

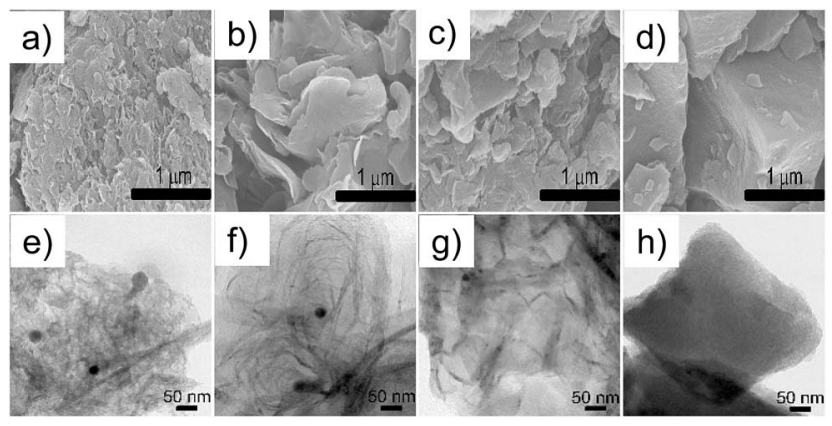

Fig. 3 SEM and TEM images of MIm + Fe-C ( $a$ and $e), I L-1-C$ ( $b$ and $f$ ) IL-2-C ( $C$ and $g$ ) and IL-3-C ( $d$ and h). The scale bars in the SEM and TEM images represent $1 \mu \mathrm{m}$ and $50 \mathrm{~nm}$, respectively.

catalysts by manipulating the stiffness of the substituent in the cation.

It is also important to identify the types of $\mathrm{N}$ that are present to help confirm whether these $\mathrm{N}$ atoms can serve as active sites. Therefore, the detailed chemical environments of the $\mathrm{N}$ atoms on the surface of the catalysts were investigated using X-ray photoelectron spectroscopy (XPS). The N 1s XPS spectra of all samples (Fig. 2d) could generally be deconvolved into four peaks at $398.3 \mathrm{eV}, 400.0 \mathrm{eV}, 401.0 \mathrm{eV}$, and $402.3 \mathrm{eV}$, which were assigned to pyridinic (N1), pyrrolic (N2), graphitic (N3), and oxidized $\mathrm{N}^{+}-\mathrm{O}^{-}$(N4) nitrogen species ${ }^{28,38}$ (Fig. 2e), respectively. It was found that pyridinic $\mathrm{N}(36.2 \%)$ and graphitic $\mathrm{N}(34.1 \%)$ were the major $\mathrm{N}$ species in IL-1-C, and pyrrolic $\mathrm{N}$ species only accounted for $22.3 \%$. However, when the $\mathrm{H}$ atom in the imidazolium cation was replaced by a rigid cyanobenzyl group (IL-3), the content of pyrrolic $\mathrm{N}$ species in IL-3-C greatly increased to $47.9 \%$, which was more than double that of IL-1-C. It was suggested that the more rigid substituent in the imidazolium cation led to fewer pyridinic $\mathrm{N}$ and graphitic $\mathrm{N}$ species. In addition, fewer pyridinic and graphitic $\mathrm{N}$ species (total 59.0\%) were observed in $\mathbf{M I m}+\mathbf{F e - C}$ than in IL-1-C (70.3\%), which evidently confirmed that well-distributed iron on the molecular level had a positive effect in increasing the content of pyridinic and graphitic $\mathrm{N}$ species during pyrolysis. Thus, different types of $\mathrm{N}$ species were produced selectively by changing the substituent in the cation and the distribution of iron in the anion of ILs.

In spite of extensive studies, the detailed contributions of the extent of graphitization, surface area/microstructure, type/amount of $\mathrm{N}$ dopants, and Fe species in doped carbon to its catalytic activity in the ORR are still controversial. ${ }^{24,39-42}$ This was presumably due to the complexity of previous research processes, which often involved multiple interfaces between precursors, supports and templates and sophisticated pyrolysis steps such as secondary high-temperature annealing,, ${ }^{43,44}$ resulting in a lack of sufficient consistency for a fair comparison. As has been shown, in our study the proposed preparation of $\mathrm{Fe}-\mathrm{N} / \mathrm{C}$ catalysts almost entirely relied on the facile manipulation of the molecular structures of IL precursors, which made the system simple. This advantage is supposedly ascribed to the unique molecular structure of the imidazolium-based IL precursors: (1) the imidazolium core group acted as the major feedstock of C and N; (2) the substituent on the imidazolium ring largely determined the porosity and influenced the type of $\mathrm{N}$ dopant; and (3) a homogeneous distribution of Fe ion on the molecular level via cation-anion interactions would promote $\mathrm{C}-\mathrm{C}$ and $\mathrm{C}-\mathrm{N}$ bonding in a honeycomb manner. Moreover, a series of $\mathrm{Fe}-\mathrm{N} / \mathrm{C}$ catalysts with tunable structures and activities could also be obtained by the appropriate selection of the substituent and the distribution of Fe ions in imidazoliumbased ILs. Both of these two features are much preferred for studies of the correlation between the structures and activities of the catalysts as follows.

Electrical conductivity is a vital parameter for determining the feasibility of electron transfer across interfaces between the substrate electrode, electrocatalyst, and oxygen in the ORR. In general, a large extent of graphitization corresponds to high conductivity. Moreover, the doping of electron-rich active $\mathrm{N}$ species, which generates a donor state above the Fermi energy level $^{45}$ and increases the electron density, ${ }^{46}$ also favors fast electron transfer in a catalytic ORR. For this reason, the specific electrical resistances of the as-prepared $\mathrm{Fe}-\mathrm{N} / \mathrm{C}$ catalysts were close to or even superior to that of graphite. It was observed that as the value of $I_{\mathrm{G}} / I_{\mathrm{D}}$ in the Raman spectra and the contents of pyridinic and graphitic $\mathrm{N}$ increased, the conductivity increased 

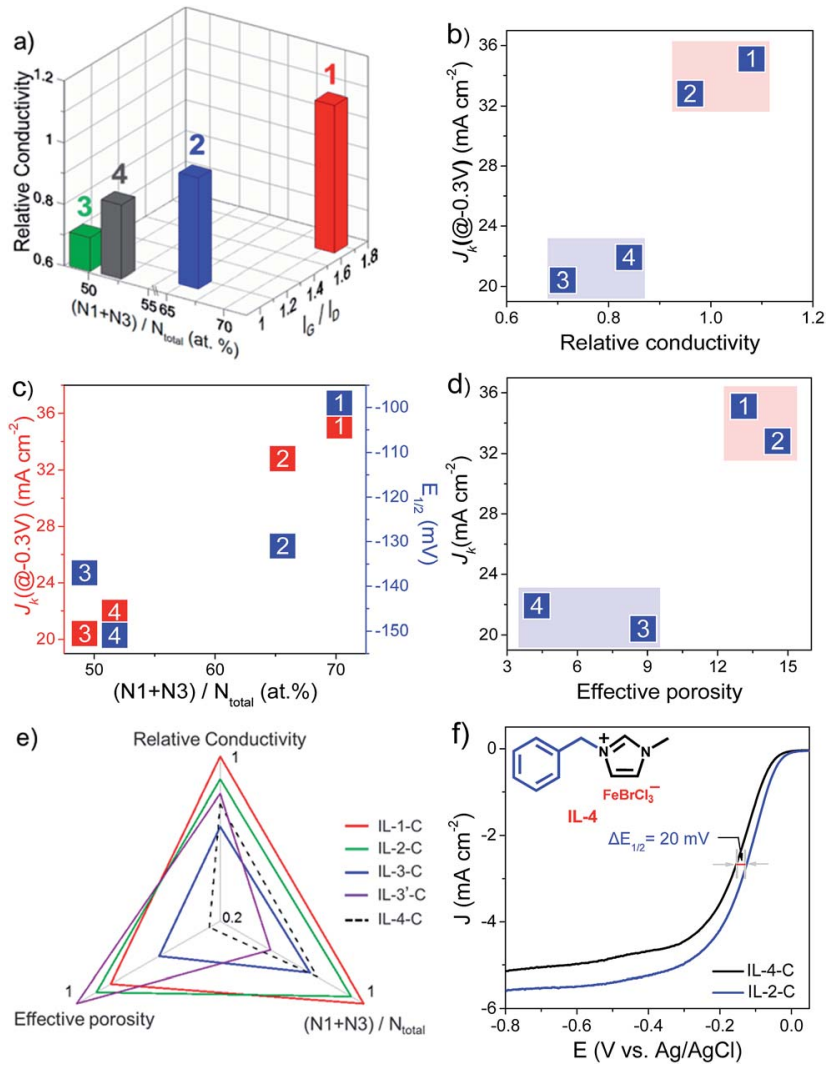

Fig. 4 Structure-activity relationships of catalysts. (a) Conductivity of catalysts versus $I_{G} / I_{D}$ and $N 1 / N 3$ content. (b) Relationship between the conductivity of catalysts and $J_{\mathrm{K}}$. (c) $J_{\mathrm{K}}$ and $E_{1 / 2}$ of catalysts plotted against N1/N3 content. (d) Relationship between the effective porosity and $J_{K}$. (e) Proposed radar plot showing the dependence of activity in the ORR on conductivity, N1/N3 content, and effective porosity. 1, 2, 3 and 4 represent IL-1-C, IL-2-C, IL-3-C and IL-4-C, respectively. (f) LSV curves of IL-2-C and IL-4-C at $1600 \mathrm{rpm}$ at a sweep rate of $10 \mathrm{mV} \mathrm{s}^{-1}$ in $\mathrm{O}_{2}$-saturated $0.1 \mathrm{M} \mathrm{KOH}$. $J_{\mathrm{K}}$ was calculated at $-0.3 \mathrm{~V}$.

(Fig. 4a). For instance, IL-1-C, which had the highest content of pyridinic and graphitic $\mathrm{N}$ and value of $I_{\mathrm{G}} / I_{\mathrm{D}}$ in this study, exhibited the highest electrical conductivity. Accordingly, the values of $J_{\mathrm{K}}$ of the as-prepared catalysts in the kinetic limiting regions increased approximately with the electrical conductivity (Fig. 4b). The type and amount of $\mathrm{N}$ dopants, which are further key factors for high catalytic activity in the ORR, were supposed to influence the values of $E_{1 / 2}$ and $J_{\mathrm{K}}$, respectively. It was found that pyridinic N (N1) and graphitic $N(\mathrm{~N} 3)$ were more active in the catalytic reduction of oxygen, and a higher content of them generally corresponded to a higher value of $J_{\mathrm{K}}$, as shown in Fig. 4c.

The performance of $\mathrm{Fe}-\mathrm{N} / \mathrm{C}$ catalysts was also largely dependent on their surface area and pore structure, which determined the amount of accessible active sites and the mass transport properties of species relevant to the $\mathrm{ORR}\left(\mathrm{H}^{+} / \mathrm{OH}^{-}, \mathrm{O}_{2}\right.$, and $\left.\mathrm{H}_{2} \mathrm{O}\right){ }^{47}$ However, activity in the ORR was not simply dependent on the total BET surface area, most of which consisted of micropores. It was suggested that mesopores of larger size would be more preferred for the migration of species relevant to the ORR, as well as higher electrochemical and chemical accessibility of catalytic active sites. Thus, the mesopore surface area (MSA) and mesopore capacity (MC) jointly affected activity in the ORR. In this sense, a single quantitative criterion that encompassed both of these textural factors was roughly proposed by multiplying MSA by MC and defined as "effective porosity" to correlate the performance in the ORR of Fe-N/C catalysts. It was noted that IL-1-C and IL-2-C, which had a high "effective porosity" (Table 1), displayed high values of $J_{\mathrm{K}}$ (Fig. 4d). In contrast, IL-3-C, despite possessing the largest total BET surface area in this study and a high mesopore surface area, exhibited a low value of $J_{\mathrm{K}}$, which could be ascribed to its low mesopore capacity.

Nevertheless, it should be noted that the catalytic activity in the ORR of the as-synthesized $\mathrm{Fe}-\mathrm{N} / \mathrm{C}$ catalysts was jointly influenced by their electrical conductivity, type/amount of $\mathrm{N}$ dopants, and "effective porosity", but not by one of these factors alone. For instance, compared with IL-1-C, although MIm + Fe-C had a high "effective porosity", it exhibited a low value of $J_{\mathrm{K}}$. This phenomenon was attributed to the uneven dispersion of iron in the precursor $\mathbf{M I m}+\mathbf{F e}$, which led to the agglomeration of iron species and loss of active $\mathrm{N}$ species $(\mathrm{N} 1+\mathrm{N} 3)$ during pyrolysis (Table 1$)$. In this respect, a radar chart, which consisted of normalized electrical conductivity, type/amount of $\mathrm{N}$ dopants, and "effective porosity", is proposed in Fig. 4e. It was generally revealed that catalysts that lay on the outer line exhibited superior catalytic activity in the ORR.

To confirm the correspondence between the electrical conductivity, type/amount of $\mathrm{N}$ dopants, and "effective porosity" for the performance in the ORR of $\mathrm{Fe}-\mathrm{N} / \mathrm{C}$ catalysts, the precursor IL-4 with a benzyl substituent, of which the rigidity was greater than that of IL-2, was prepared. Structural characterization of the carbonized product (IL-4-C) demonstrated a normalized content of pyridinic and graphitic $\mathrm{N}$ of 0.74 , an electrical conductivity of 0.77 , and an "effective porosity" of 0.26 , all of which were less than those of IL-2-C (Fig. 4e). According to a preliminary inspection of the proposed radar chart, we could predict that the catalytic activity of IL-4-C would be inferior to that of IL-2-C. Interestingly, an electrochemical study showed that the activity in the ORR of IL-4-C (Fig. 4f), including the values of $J_{\mathrm{K}}$ and $E_{1 / 2}$ (Fig. 4c), was inferior to that of IL-2-C, which was in agreement with the proposed correspondence between the structural features and the performance in the ORR of $\mathrm{Fe}-\mathrm{N} / \mathrm{C}$ catalysts. Moreover, it is highly foreseeable that by the further modulation of $\mathrm{Fe}-\mathrm{N} / \mathrm{C}$ catalyst structures via the facile combination of an unlimited range of cations/anions in IL-based precursors, and evaluation of the corresponding activities, the reliability of the correlations between the structure and activity of catalysts, which was demonstrated by using the radar plot, would be improved. Thus, by using an IL platform, the proposed radar chart (Fig. 4e) provides a feasible way of predicting the activity in the ORR of Fe-N/C catalysts merely from their textural features, which would greatly facilitate the design and preparation of highly active catalysts for the ORR.

\section{Conclusion}

In summary, highly efficient $\mathrm{Fe}-\mathrm{N} / \mathrm{C}$ electrocatalysts were successfully developed from versatile imidazolium-based ILs 
with halogen-coordinated iron anions. Owing to the unique molecular structure of the IL precursors, no supports, templates or multi-step pyrolysis were required for the preparation of the catalysts. Moreover, by taking advantage of the free combination of cations and anions in the IL precursors, a diverse range of $\mathrm{Fe}-\mathrm{N} / \mathrm{C}$ catalysts with tunable electrical conductivity, type/amount of $\mathrm{N}$ dopants, and "effective porosity" (mesopore surface area and mesopore capacity, instead of total surface area) were obtained. Based on this, it was revealed that the electrocatalytic activity depended jointly on all of these textural characteristics. Accordingly, a radar chart was also further proposed to provide a feasible way of predicting the activity in the ORR of $\mathrm{Fe}-\mathrm{N} / \mathrm{C}$ catalysts merely from their structural features. The proposed strategy for the preparation of $\mathrm{Fe}-\mathrm{N} / \mathrm{C}$ catalysts would not only be promising in the development of high-performance catalysts for practical applications of the ORR, but also offer a novel platform for studying the relationships between processing, structure and activity.

\section{Acknowledgements}

This study was financially supported in part by the National Natural Science Foundation of China (21203023, 91333110, and 21305065), Natural Science Foundation of Jiangsu Province (BK2012317, BK20130788), and the Fundamental Research Funds for the Central Universities.

\section{References}

1 L. M. Dai, Y. H. Xue, L. T. Qu, H. J. Choi and J. B. Baek, Chem. Rev., 2015, 115, 4823-4892.

2 M. K. Debe, Nature, 2012, 486, 43-51.

3 Y. Nie, L. Li and Z. D. Wei, Chem. Soc. Rev., 2015, 44, 21682201.

4 E. Proietti, F. Jaouen, M. Lefevre, N. Larouche, J. Tian, J. Herranz and J. P. Dodelet, Nat. Commun., 2011, 2, 416.

5 X. J. Zhou, J. L. Qiao, L. Yang and J. J. Zhang, Adv. Energy Mater., 2014, 4, 130123.

6 H. Shi, Y. F. Shen, F. He, Y. Li, A. R. Liu, S. Q. Liu and Y. J. Zhang, J. Mater. Chem. A, 2014, 2, 15704-15716.

7 A. Zitolo, V. Goellner, V. Armel, M. T. Sougrati, T. Mineva, L. Stievano, E. Fonda and F. Jaouen, Nat. Mater., 2015, 14, 937-942.

8 Y. Zhao, K. Watanabe and K. Hashimoto, J. Am. Chem. Soc., 2012, 134, 19528-19531.

9 R. Jasinski, Nature, 1964, 201, 1212-1213.

10 H. T. Chung, J. H. Won and P. Zelenay, Nat. Commun., 2013, 4, 1922.

11 L. B. Lv, T. N. Ye, L. H. Gong, K. X. Wang, J. Su, X. H. Li and J. S. Chen, Chem. Mater., 2015, 27, 544-549.

12 J. Wang, K. Wang, F. B. Wang and X. H. Xia, Nat. Commun., 2014, 5, 5258.

13 M. L. Xiao, J. B. Zhu, L. G. Feng, C. P. Liu and W. Xing, Adv. Mater., 2015, 27, 2521-2527.

14 Y. C. Wang, Y. J. Lai, L. Song, Z. Y. Zhou, J. G. Liu, Q. Wang, X. D. Yang, C. Chen, W. Shi, Y. P. Zheng, M. Rauf and S. G. Sun, Angew. Chem., Int. Ed., 2015, 54, 9907-9910.
15 J. Masa, W. Xia, M. Muhler and W. Schuhmann, Angew. Chem., Int. Ed., 2015, 54, 10102-10120.

16 H. R. Byon, J. Suntivich and Y. Shao-Horn, Chem. Mater., 2011, 23, 3421-3428.

17 J. S. Lee, G. S. Park, S. T. Kim, M. L. Liu and J. Cho, Angew. Chem., Int. Ed., 2013, 52, 1026-1030.

18 W. H. Niu, L. G. Li, X. J. Liu, N. Wang, J. Liu, W. J. Zhou, Z. H. Tang and S. W. Chen, J. Am. Chem. Soc., 2015, 137, 5555-5562.

19 J. Liang, R. F. Zhou, X. M. Chen, Y. H. Tang and S. Z. Qiao, Adv. Mater., 2014, 26, 6074-6079.

20 Z. S. Wu, L. Chen, J. Z. Liu, K. Parvez, H. W. Liang, J. Shu, H. Sachdev, R. Graf, X. L. Feng and K. Mullen, Adv. Mater., 2014, 26, 1450-1455.

21 Z. H. Xiang, Y. H. Xue, D. P. Cao, L. Huang, J. F. Chen and L. M. Dai, Angew. Chem., Int. Ed., 2014, 53, 2433-2437.

22 Z. H. Wen, S. Q. Ci, Y. Hou and J. H. Chen, Angew. Chem., Int. Ed., 2014, 53, 6496-6500.

23 L. Lin, Q. Zhu and A. W. Xu, J. Am. Chem. Soc., 2014, 136, 11027-11033.

24 H. W. Liang, W. Wei, Z. S. Wu, X. L. Feng and K. Mullen, J. Am. Chem. Soc., 2013, 135, 16002-16005.

25 Q. Wang, Z. Y. Zhou, Y. J. Lai, Y. You, J. G. Liu, X. L. Wu, E. Terefe, C. Chen, L. Song, M. Rauf, N. Tian and S. G. Sun, J. Am. Chem. Soc., 2014, 136, 10882-10885.

26 G. G. Eshetu, M. Armand, B. Scrosati and S. Passerini, Angew. Chem., Int. Ed., 2014, 53, 13342-13359.

27 S. G. Zhang, M. S. Miran, A. Ikoma, K. Dokko and M. Watanabe, J. Am. Chem. Soc., 2014, 136, 1690-1693.

28 Y. J. Sa, C. Park, H. Y. Jeong, S. H. Park, Z. Lee, K. T. Kim, G. G. Park and S. H. Joo, Angew. Chem., Int. Ed., 2014, 53, 4102-4106.

29 N. R. Sahraie, J. P. Paraknowitsch, C. Gobel, A. Thomas and P. Strasser, J. Am. Chem. Soc., 2014, 136, 14486-14497.

30 Z. L. Li, G. L. Li, L. H. Jiang, J. L. Li, G. Q. Sun, C. G. Xia and F. W. Li, Angew. Chem., Int. Ed., 2015, 54, 1494-1498.

31 W. Yang, T. P. Fellinger and M. Antonietti, J. Am. Chem. Soc., 2011, 133, 206-209.

32 M. Dobbelin, V. Jovanovski, I. Llarena, L. J. C. Marfil, G. Cabanero, J. Rodriguez and D. Mecerreyes, Polym. Chem., 2011, 2, 1275-1278.

33 J. Gao, J. Q. Wang, Q. W. Song and L. N. He, Green Chem., 2011, 13, 1182-1186.

34 Y. J. Zhang, K. Fugane, T. Mori, L. Niu and J. H. Ye, J. Mater. Chem., 2012, 22, 6575-6580.

35 J. T. Zhang, Z. H. Zhao, Z. H. Xia and L. M. Dai, Nat. Nanotechnol., 2015, 10, 444-452.

36 Y. G. Li, W. Zhou, H. L. Wang, L. M. Xie, Y. Y. Liang, F. Wei, J. C. Idrobo, S. J. Pennycook and H. J. Dai, Nat. Nanotechnol., 2012, 7, 394-400.

37 C. H. Choi, S. H. Park and S. I. Woo, ACS Nano, 2012, 6, 70847091.

38 R. Arrigo, M. Havecker, S. Wrabetz, R. Blume, M. Lerch, J. McGregor, E. P. J. Parrott, J. A. Zeitler, L. F. Gladden, A. Knop-Gericke, R. Schlogl and D. S. Su, J. Am. Chem. Soc., 2010, 132, 9616-9630. 
39 F. Jaouen, E. Proietti, M. Lefevre, R. Chenitz, J. P. Dodelet, G. Wu, H. T. Chung, C. M. Johnston and P. Zelenay, Energy Environ. Sci., 2011, 4, 114-130.

40 W. Ding, Z. D. Wei, S. G. Chen, X. Q. Qi, T. Yang, J. S. Hu, D. Wang, L. J. Wan, S. F. Alvi and L. Li, Angew. Chem., Int. Ed., 2013, 52, 11755-11759.

41 T. Xing, Y. Zheng, L. H. Li, B. C. C. Cowie, D. Gunzelmann, S. Z. Qiao, S. M. Huang and Y. Chen, ACS Nano, 2014, 8, 6856-6862.

42 J. Wu, W. M. Li, D. Higgins and Z. W. Chen, J. Phys. Chem. C, 2011, 115, 18856-18862.
43 K. Strickland, M. W. Elise, Q. Y. Jia, U. Tylus, N. Ramaswamy, W. T. Liang, M. T. Sougrati, F. Jaouen and S. Mukerjee, Nat. Commun., 2015, 6, 7343.

44 G. Wu, K. L. More, C. M. Johnston and P. Zelenay, Science, 2011, 332, 443-447.

45 L. F. Lai, J. R. Potts, D. Zhan, L. Wang, C. K. Poh, C. H. Tang, H. Gong, Z. X. Shen, L. Y. Jianyi and R. S. Ruoff, Energy Environ. Sci., 2012, 5, 7936-7942.

46 F. G. Sun, J. T. Wang, H. C. Chen, W. C. Li, W. M. Qiao, D. H. Long and L. C. Ling, ACS Appl. Mater. Interfaces, 2013, 5, 5630-5638.

47 Z. Y. Wu, X. X. Xu, B. C. Hu, H. W. Liang, Y. Lin, L. F. Chen and S. H. Yu, Angew. Chem., Int. Ed., 2015, 54, 8179-8183. 